\title{
ITALO-AUSTRALIAN TRANSNATIONAL HOUSES: BUILT FORMS ENHANCING SOCIAL CAPITAL
}

\author{
Dr Raffaello Furlan \\ Assistant Professor \\ College of Engineering, Department of Architecture and Urban Planning \\ Qatar University, Doha, State of Qatar
}

\section{Dr Laura Faggion}

*Corresponding Author's email address: raffur@gmail.com, laurafaggion2@gmail.com

\begin{abstract}
The literature reveals that culture, as a way of life, is a factor determining the house's spatial form, which, in turn, can contribute to the construction and/or enhancement of social capital. Scholars also stress that in the past the study of the relationship between houses' spatial form and social capital has focused on physical spatial environments at macro scale, neglecting the investigation of micro-scale housing. Namely, regardless of the interest to this relationship, direct assessment of the extent to which the spatial form of transnational houses contributes to the formation and enhancement of social capital in a host built environment is still rare in the field. The specific objective of this paper is to explore how the spatial form of Italian transnational houses in Australia contributed to the formation of social capital. It is argued that the spatial form of houses built by Italian migrants in post WWII Brisbane was conceptualized as means of re-establishing and enhancing social activities and/or interactions, and therefore contributed to the formation and enhancement of social capital. In order to provide an answer to the main question, the system of social activities performed within the domestic setting was investigated. Data obtained from visual material and interviews with participants was analyzed in order to reveal how the spatial form of Italian transnational houses enhanced social capital.
\end{abstract}

Keywords: Architectural Sociology; Migrants; Culture; Social Activities; Transnational Houses, Social Capital.

\section{INTRODUCTION: THE DISCIPLINARY CONTEXT}

An investigation of the literature reveals that the house, the place where on a daily basis family members share their life, is seen as the physical expression of interacting cultural needs. Due to the need to create contemporary spatial environments responding to users' cultural needs or simply to humanize the built form, social researchers and practitioners pointed out the necessity of re-evaluating a theoretical cultural framework in the architectural design of the built form (Rapoport, 1969, 1982a, 1982b, 1997, 2000). This approach, aiming to humanize spatial environments, is defined as humanistic in opposition to a 'formalistic approach', which focuses mostly on the appearance of buildings (Rogers \& Gumuchdjjan, 1996, p. 107; 2003, p. 7) (Zevi, 1948, p. 68).

In response to the recognition that much contemporary architecture, in its pursuit of economic and technological efficiency, has paid little attention to its human context, the last two decades of architectural studies have been marked by a renewed interest in the way designed built environments are related to users' specific needs, which are expressions of culture as way of life (Rapoport, 2000). This triggered the birth of the 'social design movement', whose purpose was to create physical designed environments responding to occupants' specific needs (Sommer, 1983, pp. 92-108) and to encourage practitioners to become more sensitive to the human context 
of the designed built form. In the 1980s, researchers from various social sciences conducted extensive research and gained insights into the relationship between human context and designed physical spatial environments. Notably, architectural sociology, a specialized field defined as the study of how human behavior and/or activities are projected onto the spatial form of buildings, emerged during this time (R. Smith \& Bugni, 2003, p. 8).

Smith and Bugni (2006), who created a resource that addresses many aspects of the relatively new discipline of architectural sociology, argue that the designed physical space, ranging from macro-scale level built environment (big-scale cities) to micro-scale built form (small-scale buildings), influences and, at the same time, is influenced by the behavior and/or activities of its occupants. Additionally, they state that it is virtually impossible for any human behavior to reside outside of cultural influence, because behavior and culture interact continually throughout development. Therefore, they emphasize that while the focus of investigation is the relationship between spatial environment and human behavior, the role of culture must also be explored. More specifically, architectural sociologists argue that an analysis of human behavior and/or activities, which are a response to specific cultural needs in turn dictated by culture as a way of life, can provide an understanding of how the users shaped the form of their settings. Therefore, architectural sociologists aim to apply their theories and research methods to the architectural design process, with the purpose of creating designed physical environments responding to users' specific cultural needs, or simply humanizing them (R. Smith \& Bugni, 2006).

My own view is that architecture is a reflection of behavior or the use of space which, in turn, is a reflection of culture; the use of space is the result of highly culture-specific and at times temporal-specific designs (Kent, 1997, p. 3).

Architectural sociology is the most relevant discipline to the context of this research study because its objective is to explore and understand how the fulfilment of Italian migrants' behavior and/or activities had priority in the architectural design process of their transnational houses in Brisbane, and consequently contributed to a humanization of the spatial environment.

In order to fill this gap, this paper constructs a theoretical framework to understand the extent to which the internal spatial distribution of a specific typology of dwelling, the archetypal 'house on a quarter-acre block' built in post-WWII Brisbane, was conceived in response to human behavior and/or activities and, furthermore, contributed to the formation and enhancement of social capital.

\section{BACKGROUND}

The aim of this section is to outline the parameters of the research study, to establish a conceptual framework for an exploration of the topic under investigation and to address the research question. In this section critical attention to basic narratives and to the theoretical resources found in the relevant literature are outlined. Namely, scholars' views, exploring the extent to which settlement patterns and housing spatial form contribute to the enhancement of social interactions, were reviewed. Researchers' insights allowed the construction and implementation of a conceptual framework, firstly for the exploration of the way the spatial form of migrants' houses contributed towards the formation and enhancement of social interactions and secondly for the analysis of the empirical data for this study.

\section{The focus of the research study}

The literature reveals that in spite of a focus by architectural sociology on the relationship between human behavior (and/or activities) and physical environments at any scale, ranging from built environment to built forms, in the past the discipline has not given much attention to the investigation of micro-scale housing (R. Smith \& Bugni, 2002b, 2002c, 2006). Scholars stress that the architectural sociology field now contains a large body of findings relevant to job satisfaction, 
expression of emotion at work, space-design influence of organizational well-being, the impact of buildings on human behavior in business, organizational-development and effectiveness. Social researchers have described how physical designed environments reflect managerial philosophies, while analysing how they subsequently impact on the participants, processes and outcomes of the organization (R. Smith \& Bugni, 2002c). Bugni and Smith (2003) have also highlighted how architectural sociologists in the past have mostly focused either on matters related to people and organizations that often involve workspace design, choice of furnishings, layout of work stations and location of conference and break rooms. As scholars highlight, the link between built environment and human activities has also been of great interest to the field of urban planning, particularly to the subfield of urban design, zoning planning and transportation planning, which is the object of study of a discipline named urban sociology (Handy, Boarnet, Ewing, \& Killingsworth, 2002).

This gap in the literature is also asserted by Amos Rapoport (1969, p. 5), who undertook extensive research, dating from as early as 1969, on the relationship between built form and culture, namely in a cross-cultural context (King, 1984, p. 4). In his pioneer work, Rapoport claimed that the interest in the way human behavior and/or activities influence the form of domestic dwellings, the most typically vernacular building type, is frequently neglected by architects, sociologists and multi-disciplinary researchers, who are more interested in studying cultural preferences embedded in built forms at a macro scale rather than a micro scale level (King, 1984, p. 6). Furthermore, as Rapoport states, the interrelationship of the built form and human behavior and/or activities has not been extensively investigated in a cross-cultural vernacular housing context. In this setting, as Rapoport notes (1982a), vernacular houses built by their users in an alien built environment are referred to as 'transnational houses'. Consequently, broadly this study endeavours to bridge the gap in the knowledge concerning the comprehension of the relationship between human behavior (and/or activities) and the spatial form of buildings, and specifically in the detailed micro-scale context of vernacular and transnational houses (Poulsen \& Lange, 1998; Rapoport, 1982a).

\section{House's spatial form as manifestation of culture}

In this section a brief explanation of the relationship between buildings and human activities is presented. As highlighted below by King, all buildings are produced as per societies' sociocultural factors, which are changed and modified as per societies' cultural needs. This means that as needs in societies change, so building forms change: buildings serving the same function may have different forms in different societies at a different period of time.

Buildings result from social and cultural needs and accommodate a variety of functionseconomic, social, political, religious and cultural. Their size, appearance, location and form are governed not simply by physical factors (climate, material or topography) but by society's ideas, its forms of economic and social organisation, its distribution of resources and authority, its activities, and the beliefs and values which prevail at any one period of time (King, 1984, p. 1).

In this way, it might be possible to see how the ideas, values, beliefs, activities, relationships and forms of social organization of particular institutions were related to the form and plan of particular buildings, and also to see how changes in institutions were reflected in changed building form (King, 1984, p. 10).

In their historical study of residential units located in Anatolia, scholars highlight how cultural and social characteristics influence the form of the settlement. They stress that the spatial configuration of the settlement and the house must be analyzed within its social and cultural context. Its spatial form is the result of a socio-cultural multi-layered interaction, and not an outcome of just physical effects. Therefore, socio-cultural factors must be analyzed in order to 
understand how way of life, as well as materials and technology of a specific period, have influenced the built form. In their words:

"Traditional house architecture and its traditional fabric constitute a live museum, which reflects history, culture, lifestyle and world views of a society. The house is a cultural phenomenon. Its form and organization are influenced by the cultural environment it belongs to. Social infrastructure of communities is in a state of constant transformation. Together with this process, people's expectations from their environments and inhabited spaces were subjected to change." (Erdogan \& Erkis, 2014, p. 117)

$\cdots$

"Houses are designed in accordance with the user needs and they are indicators of customs and traditions narrating culture of life" (Erdogan \& Erkis, 2014, p. 119)

Furthermore, in their behavioural study of the form of traditional Souqs, scholars investigated the extent to which urban spaces are influenced by users socio-cultural factors, which in turn affect human behavior. Spatial form is influenced by activities in turn dictated by human needs. They argue that spatial form and socio-cultural factors are interrelated: there is a mutual relationship between space and human beings, where factors of use and functionality of the space is the manifestation of people socio-cultural needs (Al-Maimani, Salama, \& Fadli, 2014).

In his book called 'House, Form and Culture', Rapoport (1969) argues that the form of the house is related 'to culture as a way of life, world view and form of social organizations' (King, 1984, p. 4), where by culture it is meant 'a group of people who have a set of values and beliefs, which embody ideals and which are transmitted to members of the group through enculturation' (Rapoport, 1984, p. 286). Rapoport stresses that through an investigation and analysis of the activities performed within the domestic space by the family members, it is possible to understand how the users distributed and utilized the space of their houses and the extent of which human beings' culture, namely specific needs and way of life, has influenced the spatial form of the house. This approach is also emphasized by Oliver who stresses that the built environment is a reflection of behavior, which has to be considered in the context of activities (Oliver, 1997, p. 16). Furthermore, Rapoport highlights the importance and the need to dismantle the concept of activities into its variables, as he did with the concept of socio-cultural variables. He identifies six components, which, in his theories, represent the system of activities. He highlights the variability of the activity which involves (1) the nature of the activity itself (what), (2) the persons involved or excluded (who), (3) the place where it is performed (where), (4) the order or sequence it occurs (when), (5) the association to other activities (how - including or excluding whom), and finally (6) the meaning of the activity (why) (Rapoport, 1969, 1982a, 1982b, 1997, 2000). He stresses the importance of studying the systems of activities, because in his words 'variability with lifestyle and ultimately culture goes up as one moves from the activity itself, through ways of carrying it out, the system of which it is part, and its meanings' (Kent, 1990, p. 11).

\section{Vernacular houses and cultural needs}

This section focuses on the type of building, which constitutes the topic of investigation. While architecture encompasses many different types of buildings, the focus of this study will be limited to vernacular architecture, and particularly to domestic dwellings, which are considered to be the most typically vernacular building type (Rapoport, 1969, p. 5). The term 'vernacular architecture' represents all buildings designed and built by their users within a bounded cultural and traditional context, in opposition to building exemplars created by formally trained architects (Oliver, 2006, p. 143; Tilley, Keane, Kuchler, Rowlands, \& Spyder, 2006, p. 230).

Specifically, Rapoport states that the form of the vernacular house is (1) the product of human beings' culture, which acts as a dominant or primary determinant, and is (2) in turn modified and/influenced by architectural responses both to climatic conditions and to limitations of materials/construction technologies, which act as secondary determinants. As Rapoport argues: 
Primary determinants affect the way we behave and how we wish to behave, the clothes we wear, the books we read, the furniture we use and how we use it, the food we eat and how we prepare and eat it, and consequently the houses and settlements in which we live and how we use them. It is these influences that make it easy to identify a house or city as belonging to a given culture or subculture $(1969$, p. 85).

Oliver, who highlights that vernacular architecture is the reflection of both components material and cultural of its builders and occupiers, share Rapoport's view. He highlights that all cultures have distinctive and unique vernacular architectural forms, which are shaped by specific needs dictated by culture as a way of life.

Vernacular architecture generally embodies community values, and less evidently, may symbolize concepts of the cosmos, or acts as an analogue for the abstractions of belief. Thus, even a simple dwelling may reflect both the material and spiritual worlds of builders and occupiers (Oliver, 1997, p. xxii).

Over time, cultures have determined the buildings that will accommodate their needs, subsequent generations drawing upon their traditions and tempering them as changing circumstances warrant (Oliver, 2006, p. xviii).

Finally, vernacular architecture has been chosen because it is considered to be more autochthonous, spontaneous and authentic compared to that designed in a professional environment. Therefore, its form can be examined as evidence of the way the users influenced it in response to both specific cultural needs. Specifically, the purpose of this research study is to investigate and analyse the system of the activities performed within the domestic space by Italian migrants in order to understand (1) how the users distributed and utilized the space of their houses and (2) the extent to which the spatial form of their houses contributed to enhance social capital.

Transnational houses as places of memory and refuge

As Foley stresses, a house comprises much more than a physical shelter for people to occupy: it encompasses the broader residential setting, including privacy, location, safety and investment (Foley, 1980, p. 457).

Scholars (Al-Thahab, Mushatat, \& Abdelmomem, 2014) argue that the concept of public/privacy realm represents a factor determining the spatial form of the house and of the organization of its social spaces. Namely, the need for privacy, which is also dictated by culture, affects the form of the house: social spaces, determined by traditional inherited behavioural values, contribute to communal social integration The house and the spatial organization of its activities have the role of holding family gathering within the living area. On the other hand, for example it is shown that the space of the entrance is shaped in order to prevent any kind of visual intrusion from outside towards the family/living room and the courtyard, which represents the main social core of the house. Therefore, the house becomes the manifestation of social and human organization and encompasses several systems of activities.

"The separation of public/private spaces summarizes the impact of the cultural and behavioural value systems on the sequence and hierarchy of spaces that largely defines the organic pattern of the traditional fabric at large" (Al-Thahab et al., 2014, p. 238).

Smith, who states that the form of the house is influenced by cultural traditions and social dynamics, also emphasizes this concept. Traditions and dynamics contribute to better understanding the development of the urban fabric and of its built forms such as houses (M. E. Smith, 2014, p. 207).

More importantly, a house provides the setting within which people live their lives in a community; the house impacts on human beings' senses, emotions, participation in physical activity and community life, sense of community, and general well-being (Israel, 2003). 
Commonly, once tenants have achieved the security that a house provides, it is then possible to transform that house into a home. A home becomes a place which can accommodate people's needs; a place reflecting and affecting people's behavior according to their cultural preferences; a place where people spend part of their time undertaking the sort of human activities determined by their own culture (Inglis, 2005, p. 10; Kent, 1997; Rapoport, 2000); a place where tenants create memories (Sarup, 1994). At this level the home becomes a physical setting providing a social space allowing occupants to meet and finally enhance their social interactions (Steele, 1973, 1983).

In addition, Rapport and Dawson (Rapport \& Dawson, 1998) stress that the transnational house is a mobile habitat which is subject to change and it cannot be perceived as a fixed physical structure. Also, Kent argues that the users tend to distribute the domestic space to perform activities, which are developed during the childhood.

The use of space is an integral part of every human being's daily life. Every day, we make subliminal and conscious decisions concerning the occasions at which a diverse range of activities will be performed. Such decisions are based on the spatial patterning that is developed in childhood through socialisation (Kent, 1984, p. 1).

These insights suggest that this perception of the house as a habitat opened to changes may strengthen migrants' desire to build and distribute their own new houses in the host country according to their past housing experience, to enhance the feeling of familiarity. Therefore, the construction process is seen as a way to create a tangible linkage between migrants' present dwelling and their desired past house. Inevitably the new transnational house built in the host built environment can become a place of memory. In addition to this interpretation, Depres (1991), in her studies of trans-national houses, emphasises that cultural groups interpreted the house as a place of refuge - reminding migrants of their origins - and a place allowing migrants to go back to the traditional activities they used to perform before emigrating.

Following these insights, the extent to which Italian migrants' housing past experience have influenced the shape of their new houses in their host environment was investigated. Specifically, it was explored how the need of creating a place of refuge reminding migrants of their origins and allowing migrants to go back to the social activities traditionally performed in previous spatial environments affected the form of their houses.

\section{Urban settlements: a setting to enhance social capital}

According to a renowned sociologist, Pierre Bourdieu (1992), who introduced concepts such as cultural, social and symbolic forms of capital, social capital derives from the cooperation, network and connections between individuals and groups. Social capital promotes cooperation among members and families of a community, therefore facilitating social integration within the community.

Scholars reveal that the formation of spaces within both the built environment (macro-scale level) and the built form (micro-level) can facilitate social activities and/or social capital (Coleman, 1988; Siegrist, 2000; Woolcock, 1998). Rapoport also points out the relationship between social capital and built environment. He highlights that it is the need of human beings to meet, to share food and finally to have a private place which affects the form of the house or its spatial configuration. He stresses the importance to investigate and understand how patterns of behavior and/or activities, which are influenced by culture as a way of life, impact on the house's spatial form.

...humans who need places to meet, to share food, to have private territories, should have differentiated among spaces and places from earliest times. 
It is therefore imperative to consider man-environment interaction both through time and cross-culturally in order to trace regularities and patterns and also in order that any generalizations which are made might be valid (Rapoport, 1984, p. 284) .

In Addition, Putnam highlights that the way we design and build the macro-scale urban setting where communities reside can have an impact on the degree to which people are involved in those communities (neighbourhoods). He stresses that it is not just the micro-scale level single house's spatial configuration, but also the surrounding built environment, enhancing a sense of community, which can enrich social interaction among the population (Putnam, 2000).

Those tangible substances [that] count for most in the daily lives of people: namely good will, fellowship, sympathy, and social intercourse among the individuals and families who make up a social unit ... The individual is helpless socially if left to himself ... If he comes into contact with the neighbour, and they with other neighbours, there will be an accumulation of social capital, which may immediately satisfy his social needs and which may bear a social potentiality sufficient to the substantial improvement of living conditions in the whole community (Putnam, 2000).

This view is shared by Smith and Bugni, who stress that the planning of a city has an impact on the way people live in the city, in a similar way as the internal layout of a house, distribution, location and size of each room within the house has an impact on the way tenants live their lives (R. Smith \& Bugni, 2003). Emphatically, the way the city and its sectors are planned has a deep impact on the way people use the city, live their daily lives and carry on their social activities. Also, according to Wilson (1997), when the built environment is shaped in a way, which does not promote social interactions and/or capital, it is the community and the individuals who get involved and gradually attempt to shape the built form to facilitate and enhance the development of social activities. This might occur through the creation of public open spaces such as porches, sidewalks and multi-use parks, which facilitates social interactions among people.

The role of public sites - as spaces of leisure, meetings and encounters - in creating possibilities to develop social activities, which stimulate new encounters and contribute to create resources of social capital among the population, is also highlighted by Huntoon (2001) and Warner (2001). The insights from these scholars suggest that the lack of public sites or public one spaces within the host built environment may strengthen migrants' desire and need to shape the spatial form of the house in order to allow them to carry out social activities. Scholars argue that the way in which people use the settlement also affects the spatial form of the house: for example in some urban contexts the meeting space can be the house while in other urban contexts the meeting space can be a street or a plaza which is part of the urban settlement. For example, Rapoport stresses how, in Latin America, the domestic space is mainly used to sleep and store things, while most social activities take place outside the house within the public open spaces of the city. In particular, Rapoport points out a relevant distinction between Latin, Mediterranean towns - where people use the settlement or the public town square area within the settlement for social activities purposes - and Anglo-American cities - where inhabitants use their house and backyard to entertain social interactions (Rapoport, 1969, 1982a, 1982b, 1997, 2000).

This suggests that for a better understanding of the way the configuration of the Italian Transnational house enhances social capital, the house cannot be studied in isolation from the Australian host settlement. It has to be explored as part of the whole macro-scale spatial system which relates the single house, the settlement and the way of life, because the spatial form of the house is not just affected by the way the users live in it and the range of social activities taking place in it, but also by the way such activities are performed in the whole built environment.

\section{QUALITATIVE RESEARCH METHODOLOGY}

The following section explores and discusses reviewed housing research approaches, perspective, strategy, case study and methods. The literature reveals that social researchers apply three different theoretical approaches for the study of housing (Clark, Deurloo, \& Dieleman, 
1984; Littlewood \& Munro, 1997; Saunders, 1989; R. Smith \& Bugni, 2002a): (1) quantitative economic or demographic studies on housing and moving patterns; (2) a qualitative approach to understanding the cultural meanings of the home to its occupants; and (3) a quantitative approach to understanding cultural differences in housing consumption and preferences.

Namely, architectural sociologists stress that the data collection methods used by social researchers, ranging from statistical to qualitative, are most applicable to architectural practice because they can assist scholars and practitioners in understanding the nature of people's specific cultural needs and their influence on the spatial form of the house. As they also highlight, the choice of method, either quantitative or qualitative, is dependent on the research objective (Sommer, 1983).

Clapman (2005), who shows that quantitative housing research uses rationalistic criteria focusing on the size and installations in the house in order to understand housing choices and consumption, argues that this is not the most appropriate criteria with which to understand the cultural influences on the form of the house by its occupants. According to Clapman (2005), the cultural influences on dwellings need to be investigated through research based on qualitative methods, in order to capture and understand the culture, as a way of life, of the occupants. Architectural sociologists (R. Smith \& Bugni, 2006) also argue that the form of the house is difficult to understand outside the context of its cultural settings.

Therefore, in attempting to gain insights into the relationship between the spatial form of Italian transnational houses in Brisbane and the users' social activities, the study employs a predominantly qualitative methodology. This is because insights into the cultural meaning that a material form has for individuals within a given social context can best be gleaned from the individuals themselves, and by exploring the rich symbolic universe within which individuals exist (Blumer, 1969).

\section{The Symbolic Interactionist Perspective}

Symbolic interactionism is the selected perspective for this study (Blumer, 1969) because of its usefulness in exploring the meanings which are produced through social interactions between human beings. Applied symbolic interactionism was developed in the early twentieth century by John Dewey, Charles Horton Cooley and George Herbert Mead, three scholars at the University of Chicago, and by Jane Addams, a practitioner with an interest in research. Although each of these thinkers sympathized with the philosophy of 'pragmatism', Dewey and Mead were interested in intellectual pragmatism, while Addams had an interest in the applied sciences. All three believed that thinking/doing, theory/practice, social science/social work, should not be separated (Forte, 2003). Dewey, Cooley, Mead and Addams asserted that objects do not have inherent meaning, but that their meaning is attributed to them (Blumer, 1969). Additionally, as these researchers emphasise, human beings shape and reshape their reality through an on going interaction with and among social objects, self and others (Blumer, 1969). Plato also established this concept of the social construction of reality:

Socrates . . . what is really true is this: the things of which we naturally say that they 'are', are in process of coming to be, as the result of movement and change and blending with one other. We are wrong when we say they 'are' since nothing ever is, but everything is coming to be (Plato \& Campbell, p. 152).

This perspective suggests that the views, perceptions and meaning Italian migrants attribute to their houses are produced and shaped by the complexity of interactions between human beings and the cultural context of the setting.

\section{Qualitative Research Strategy}

The qualitative research methodology is considered the most appropriate one to apply in the current study. Additionally, it is necessary to choose between a numbers of qualitative research 
strategies. Denzin and Lincoln (2005, p. 14) stress the importance of choosing 'a flexible set out of guidelines that connects theoretical paradigms to strategies of enquiry and methods for collecting empirical material'. They identify four sub-categories of research inquiry (Denzin \& Lincoln, 2005; Silverman, 2000): (1) phenomenology may be chosen when the subject of the research examines a deep, underlying reason for a person to believe a particular thing, or to act in a particular manner; (2) ethnography may be employed if the study is based on cultural values; (3) case study may be used when the study is of a particular person or clearly defined group; (4) grounded theory is appropriate when the researcher has no clear theory on the subject of investigation. A qualitative research study can be developed by adopting any, or a combination, of these strategies (Creswell, 2003).

\section{The Case Study}

The data collection's process started with the selection of Italian migrants, followed by the selection of their not-altered self-built artifacts (See figures 1-4-7-10). The selection of interviewees was based on clearly defined criteria. Interviewees were limited to migrants born in Italy during the 1930s and 1940s. All selected Italian migrants had migrated to Australia in the 1950s and 1960s. As all interviewees were approximately 20-30 years old at the time of their arrival in Australia, it was assumed that people who lived in their homeland for several years and migrated as young adults were preferable because they had spent enough time in Italy to assimilate a culture, as way of life belonging to a cultural group.

Additionally, social class is a 'limit' that was also taken into account. Bourdier, AISayyad, Passeron and Thompson (J. P. Bourdieu \& AlSayyad, 1989; P. Bourdieu, 1977, 1979, 1983, 1986, 1990a, 1990b, 1992, 1993, 1998; P. Bourdieu \& Passeron, 1990; P. Bourdieu \& Thompson, 1991) highlighted the fact that the concept of culture is closely related to a cultural group and to social class. In their view, each social class possessed its own habits, defined as a set of acquired patterns of thought and behavior, and generally of a way of life. Therefore, he stressed that the built form is the reflection of culture, as a way of life, of a cultural group and its social class. A house and its appearance can be linked to social identity and therefore can distinguish one social status group, and also one social class, from another. Through functional and decorative attributes, a house can be used as a marker of status and class. As mentioned earlier, this factor was considered in the selection of Italian migrants for this research study. The selected participants belonged to the working social class, since participants belonging to this specific class represented the majority of Italians who migrated to Australia (Cresciani, 1985, p. 95). Accounting for the limits listed above, the case study included 20 Italian migrant couples and four self-built not-altered houses.

\section{Methods for data collection}

The research study inevitably draws upon multiple qualitative research methods (Creswell, 2003, p. 181). Being the objective of exploring a case from different perspectives to ensure the validity of the case-study research, varied methods were employed and combined, or triangulated (Denzin, 1978). Johansson defines this process as triangulation, or 'the combination of different levels of techniques, methods, strategies, or theories, is the essence of case-study strategy' (Johansson, 2003, p. 8). Therefore, within the current study, triangulation from different sources is adopted in order to validate the findings, (Yin, 2003, p. 159).

In order to explore and understand how Italian migrants shaped their transnational house in Brisbane and contributed to the formation and enhancement of social capital, a detailed case study was required for collecting first-hand data. The chosen methods allowed collecting oral and visual data.

Oral data was collected from oral stories from Italian migrants living in Brisbane through focus groups, in depth interviews and photo elicitation. Visual data was gathered through site 
visits, field observation, visual material and photographs. An integration of methods collecting both oral and visual data was considered essential for the purpose of this research study (Creswell, 2003).

\section{FINDINGS}

Participants revealed that two main factors played a determinant role in Italian migrants' decisions to build two story houses in Australia (see figures 1-4-7-10). (1) The wish to have a house designed for their needs that is having more space to perform activities dictated by cultural needs; (2) the wish to continue the old tradition of the grand family house where interviewees had lived in Italy before migrating. Consequently the construction of two-story houses, influenced by the memory of the family house, allowed having more space to be used by the family members' to perform social activities.

All participants revealed that after working in the sugar cane fields in North Queensland, many Italians moved to Brisbane driven by the wish to live in a less isolated built environment where they would have more opportunities to socially interact among themselves and with locals. As a result, the house was distributed in order to allow social activities to be performed within the domestic context (see figures 2-3-5-6-8-9-11-12; the yellow area indicates public space and the grey one indicates private space). More specifically, participants highlighted the nature of social activities performed within the house and distinguished them into (a) informal and (b) formal social activities.

While informal activities, such as the daily family dinner, the randomly family and women meeting, were performed in the living-dining area located at the ground floor (see figures 2-5-811) and readily accessible through the front door of the house, formal activities, such as the Sundays and Christmas and Easter and general public holiday days lunch were carried out in the open area comprising living, dining and kitchen, located in the front area of the upper level (see figures 3-6-9-12).

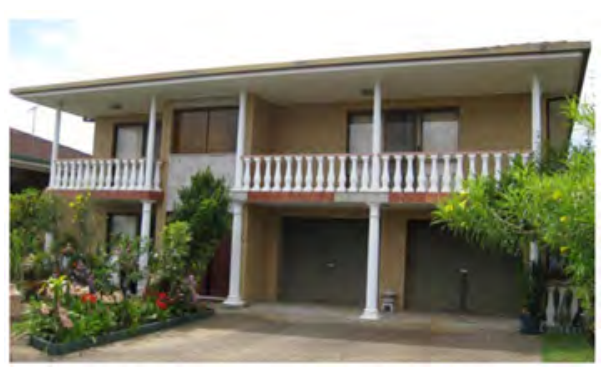

Figure 1: Front façade (Case 1) (Source: Authors)

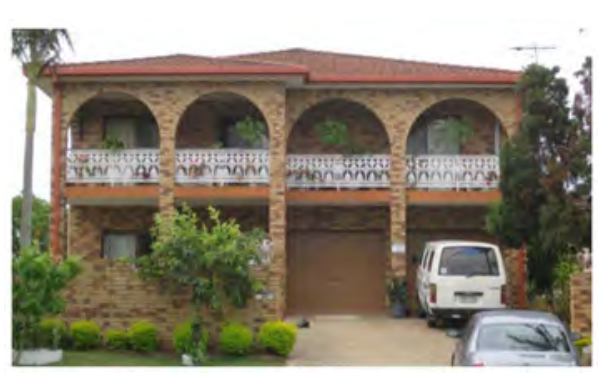

Figure 4: Front façade (case 2) (Source: Authors)

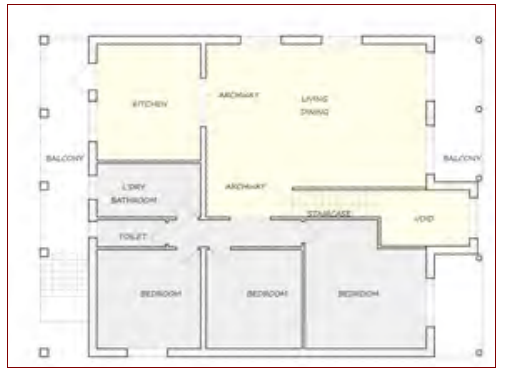

Figure 2: Ground Floor Plan (case 1) (Source: Authors)

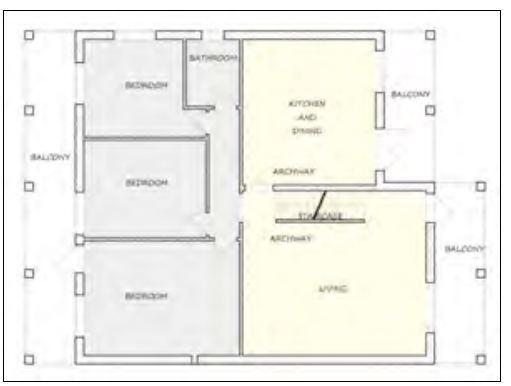

Figure 5: Ground Floor Plan (case 2) (Source: Authors)

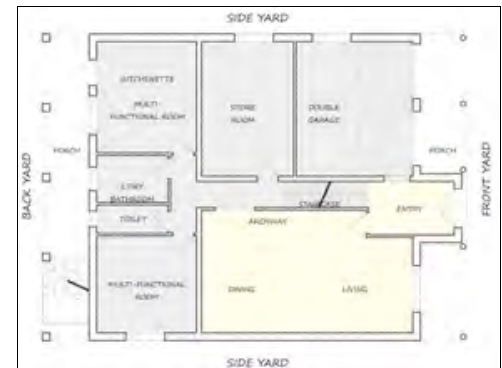

Figure 3: First Floor Plan (case 1) (Source: Authors)

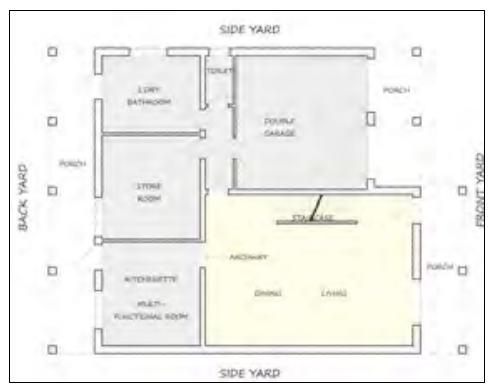

Figure 6: First Floor Plan (case 2) (Source: Authors) 


\section{ArchNet $\Gamma$}

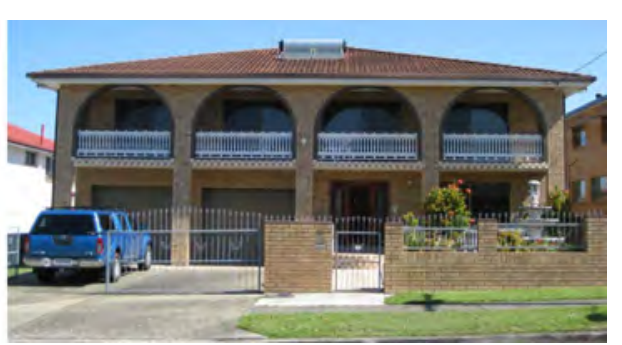

Figure 7: Front façade (case 3) (Source: Authors)

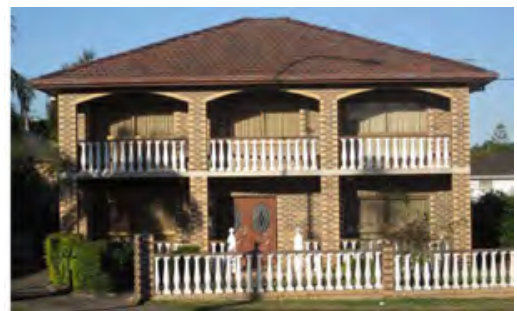

Figure 10: Front façade (case 4) (Source: Authors)

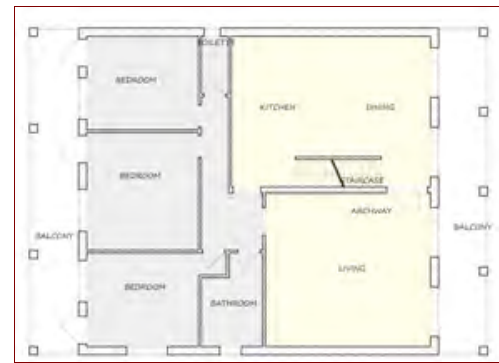

Figure 8: Ground Floor Plan (case 3) (Source: Authors)

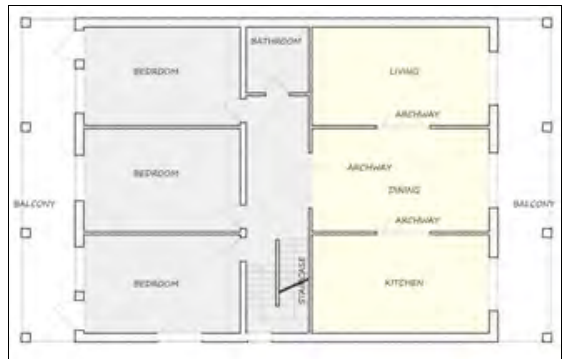

Figure 11: Ground Floor Plan (case 4) (Source: Authors)

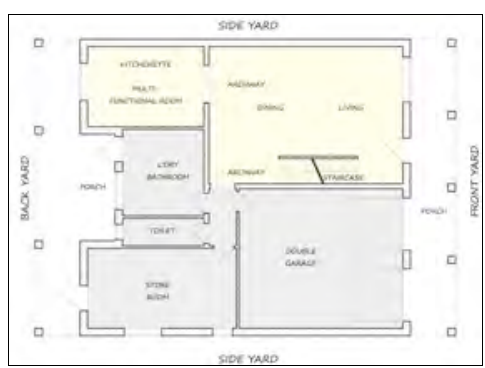

Figure 9: First Floor Plan (case 3) (Source: Authors)

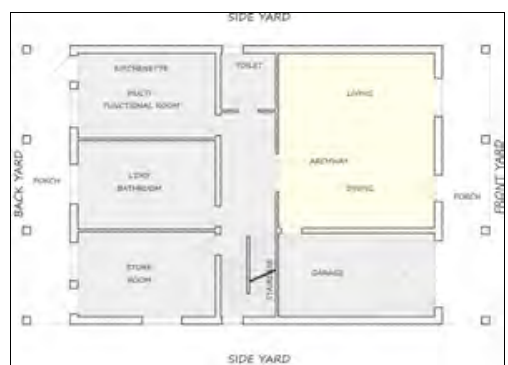

Figure 12: First Floor Plan (case 4) (Source: Authors)

The two diagrams below (figures $A$ and $B$ ) clearly summarize and explain the nature of the activities performed, the relationship between activities and spatial form of the house and the reasons behind the activities selected.

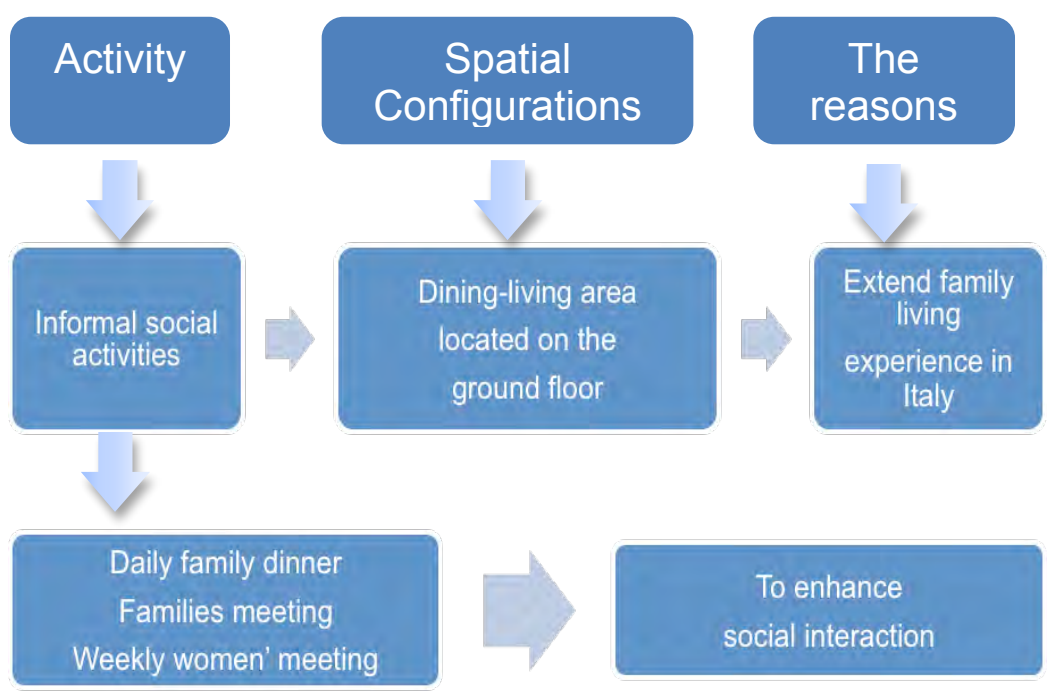

Figure A: Informal social activities (Source: Authors). 


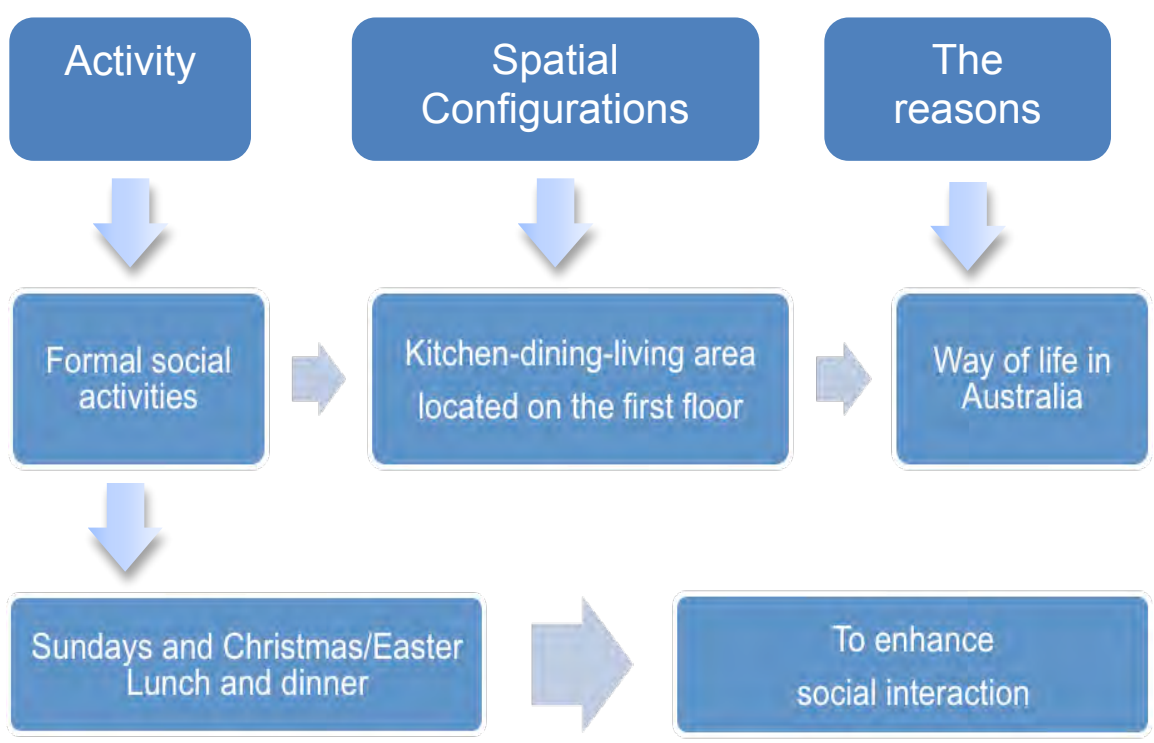

Figure B: Formal social activities (Source: Authors).

Participants highlighted that the internal layout in Italian migrants' houses was purposively conceived to enhance their social interactions among family members, relatives, friends and neighbours. As revealed, Italian migrants' houses comprised two 'daily areas' utilized for social interactions: an area comprising living and dining rooms at the ground floor utilized for informal meetings (See figures 2-5-8-11), and an area comprising kitchen, living and dining rooms at the first floor utilized for formal meetings (see figures 3-6-9-12).

The space to prepare food, cook and perform social activities is emphasized in Italian houses built in Brisbane. This occurred because (1) traditionally Italian way of life has revolved around the preparation of food, a good glass of wine and the company of friends and family; (2) in Australia many migrants had no families with them and for those, new friends met in Australia became as intimate as family, taking the roles of aunts, uncles and grandparents. Coming together over a table in their Australian transnational houses was like creating a new family network and a sense of being Italian.

The findings revealed another factor, which contributed to allocate space for social activities: the host built environment. Interviewees stressed that (3) in the 1970 s residential areas in Brisbane lacked of open public spaces, commonly used as meeting spaces, as town squares which were a urban element incorporated into the fabric of Italian cities. As a result, Italian migrants, perceiving that this lacking urban element contributed to deprive them of the possibility of socially interacting in the way they used to do back in Italy, allocated more space for social purposes within their transnational houses.

\section{CONCLUSIONS}

The findings revealed that (1) the spatial form of Italo-Australian transnational houses was shaped in response to the specific need to perform social activities dictated by cultural needs, in the attempt to adjust to, to 'tame', and to make sense of, a radically different environment, and (2) the house was interpreted as a place of memory shaped through nostalgic practice whose purpose was to enhance a sense of familiarity in the host built environment.

More specifically, the findings highlighted that urbanization patterns in an alien built environment, namely the lack of public urban spaces like a town square traditionally utilized by 
Italian migrants in their native built environment for performing social activities, had an impact on the nature of social activities performed at a macro-scale level in Brisbane. The lack of public space in the host urban settlement combined with the need to establish a social network in a situation where integrative ties have been weakened by movement to a new location influenced the way Italian migrants conceived the internal spatial distribution of their houses in Brisbane.

The house was configured with two large living areas, utilized for performing formal and informal social activities and therefore in order to enhance social interactions and/or social capital. This insight means that migration to another land represents a fundamental dislocation of social activities and, in this regard, the spatial form of the house could be conceptualized as means of re-establishing social interactions and/or enhancing social capital.

This study revealed that Italian migrants adopted a humanistic approach when they built their houses, because they constructed their artefacts in response to specific needs, based on their culture. Therefore, this study can help in translating these research findings into practice. In order to support a humanistic approach, and fill the gap between the disciplines of Architecture and Sociology, the architectural design of houses should be based upon two aims: to investigate (a) the extent to which house design can be guided by the users' cultural needs, expressed as human behaviour and/or activities; and (b) possible avenues of alternative creative designs for housing based on users' cultural need. Therefore, the involvement of residents and an evaluation of responses to forms of habitation from users within a given society can improve future planning, and can progress housing process design. Such participation would enable the users to express their needs and would facilitate a spontaneous, dynamic change. Culture as a way of life of inhabitants cannot be expressed if the environment is built through an imposed formula dictated by standardisation, speculation and for profit purposes. People can have a deciding role in the creation of their built form. They can put a visible imprint on it. Houses built by Italian migrants are an example of this concept. Their houses facilitated the mode of living of the users according to their culture.

Additionally, this study contributed to better understanding of how Italian migrants influenced the built form of the host Australian built environment and how socio-cultural factors are embedded and preserved in the built form, which represents the national cultural heritage of Australia. This exploration of a historically significant process of Australian domestic architectural development contributed to knowledge of contemporary Australian society.

\section{Acknowledgement}

The authors thank the anonymous reviewers for their comments, contributing to the improvement of this paper.

\section{References}

Al-Maimani, A., Salama, A. M., \& Fadli, F. (2014). Exploring socio-spatial Apsects of Traditional Souqs: The Case of Souq Mutrah, Oman. Archnet-IJAR, International Journal of Architectural Research, 8(1), 50-65.

Al-Thahab, A., Mushatat, S. \& Abdelmomem, M. G. (2014). Between Tradition and Modernity: Determining Spatial Systems of Privacy in the Domestic Architecture of Contemporary Iraq. Archnet-IJAR, International Journal of Architectural Research, 8(3), 238-250.

Blumer, H. (1969). Symbolic Interactionism: Perspective and Method. Englewood Cliffs, New Jersey: Prentice-Hall.

Bourdieu, J.P., \& AISayyad, N. (1989). Dwellings, Settlements and Tradition: Cross-Cultural Perspectives. Berkeley, CA: University Press of America.

Bourdieu, P. (1977). Outline of a Theory of Practice. Cambridge: Cambridge University Press.

Bourdieu, P. (1979). Algeria 1960: The Disenchantment of the World, the Sense of Honour, the Kabyle House or the World Reserved. Cambridge: Cambridge University Press.

Bourdieu, P. (1983). The field of cultural production, or: The economic world reversed. Poetics, 12(4-5), 311-356. 
Bourdieu, P. (1986). The Forms of Capital. In J. G. Richardson (Ed.), Handbook of Theory and Research for the Sociology of Education (pp. 241-258). New York: Greenwood Press.

Bourdieu, P. (1990a). In Other Words. Stanford, California: Stanford University Press.

Bourdieu, P. (1990b). The Logic of Practice. Stanford, California: Stanford University Press.

Bourdieu, P. (1992). Distinction: A Social Critique of the Judgement of Taste. London: Routledge.

Bourdieu, P. (1993). How Can One Be a Sports Fan? In S. During (Ed.), The Cultural Studies Reader (pp. 427). London: Routledge.

Bourdieu, P. (1998). The State Nobility. Cambridge, UK: Polity Press.

Bourdieu, P., \& Passeron, J.C. (1990). Reproduction in Education, Society and Culture. London: Sage Publications.

Bourdieu, P., \& Thompson, J. B. (1991). Language and Symbolic Power. Cambridge, Massachusetts: Harvard University Press.

Chapman, J. (2005). Emotionally Durable Design-Objects, Experiences and Emphathy. London: Routledge.

Clark, W.A., Deurloo, M.C., \& Dieleman, F.M. (1984). Housing Consumption and Residential Mobility. Annals of the Association of American Geographers, 74(1), 29-43.

Coleman, J.S. (1988). Social Capital in the Creation of Human Capital. American Journal of Sociology, 94, 95-120.

Cresciani, G. (1985). The Italians. Parramatta Sydney: Macarthur Press.

Creswell, J. (2003). Research Design: Qualitative, Quantitative and Mixed Methods Approaches (2 ed.). Thousand Oaks, California: Sage Publications.

Denzin, N.K. (1978). The Research Act: A Theoretical Introduction to Sociological Methods. New York: McGraw-Hill.

Denzin, N.K., \& Lincoln, Y.S. (2005). Handbook of Qualitative Research. London: Sage Publications.

Depres, C. (1991). The Meaning of Home: Literature and Directions for Future Research and Theoretical Development. The journal of Architecture and Planning Research, 8(2), 96-115.

Erdogan, Ebru, \& Erkis, S. Didem Boztepe. (2014). Sille Settlement in the Context of Sustainable Historical fabric and Facade Analysis of Its Traditiona Houses. Archnet-IJAR, International Journal of Architectural Research, 8(3), 117.

Foley, D.L. (1980). The Sociology of Housing. Annual Review of Sociology, 6(1980), 457-478.

Forte, J.A. (2003). Applied Symbolic Interactionism: Meanings, Memberships, and Social Work. In L. T. Reynolds \& N. J. Herman (Eds.), Handbook of Symbolic Interactionism (pp. 915-936). Walnut Creek: Altamira Press.

Handy, S. L., Boarnet, M. G., Ewing, R., \& Killingsworth, R. E. (2002). How the Built Environment affects Physical Activity. Views from Urban Planning. American Journal of Preventive Medicine, 23(2S), 6473.

Huntoon, L. (2001). Government Use of Nonprofit Organizations to Build Social Capital. THE JOURNAL OF SOCIO-ECONOMICS, 30(2), 157-160.

Inglis, David. (2005). Culture and Everyday Life. New York: Routledge.

Israel, T. (2003). Some Place Like Home. Using Design Psychology to Create Ideal Places. Chichester, UK: Wiley-Academy.

Johansson, R. (2003). Case Study Methodology. Paper presented at the Methodologies in Housing Research, Stockholm.

Kent, S. (1984). Analyzing Activity Areas: An Ethnoarchaelogical Study of the Use of Space. Albuquerque: University of New Mexico Press.

Kent, S. (1990). Domestic Architecture of the Use of Space: An Interdisciplinary Cross-Cultural Study. New York, Cambridge: Cambridge University Press.

Kent, S. (1997). A Cross-cultural Study of Segmentation, Architecture, and the Use of Space. In S. Kent (Ed.), Domestic Architecture and the Use of Space: an Interdisciplinary Cross-cultural Study (pp. 127-152). New York, Cambridge: Cambridge University Press.

King, A. (1984). Buildings and Society. Essays on the Social Development of the Buitl Environment. London: Routledge \& Kegan Paul.

Littlewood, A., \& Munro, M. (1997). Moving and Improving: Strategies for Attaining Housing Equilibrium. Urban Studies, 34(11), 1771-1787. 
Oliver, P. (1997). Encyclopedia of Vernacular Architecture of the World. New York: Cambridge University Press.

Oliver, P. (2006). Built to meet needs. Cultural Issues in Vernacular Architecture. London: Architectural Press.

Plato, \& Campbell, L. (2007). The Theaetetus of Plato. Oxford: The University Press, 1861.

Poulsen, M., \& Lange, A. (1998). Immigrants in Denmark. Copenhagen: Denmark Statistik.

Putnam, R.D. (2000). Bowling Alone: The Collapse and Revival of American Community. New York: Simon \& Schuster.

Rapoport, A. (1969). House, Form and Culture. New Jersey: Prentice-Hall.

Rapoport, A. (1982a). Housing and Identity. Cross-Cultural Perspectives. New York: Holmes \& Meier Publishers.

Rapoport, A. (1982b). The Meaning of the Built Environment: A Nonverbal Communication Approach. Beverly Hills, California: Sage Publications.

Rapoport, A. (1984). Vernacular Architecture and the Cultural Determinants of Form. In A. D. King (Ed.), Buildings and Society: Essays on the Social Development of the Built Environment. London, Boston and Henley: Routledge \& Kegan Paul.

Rapoport, A. (1997). Systems of Activities and Systems of Settings. In S. Kent (Ed.), Domestic Architecture and the Use of Space: an Interdisciplinary Cross-cultural Study (pp. 9-20). Cambridge: Cambridge Univeristy Press.

Rapoport, A. (2000). Culture and built form: a reconsideration. In K. D. Moore (Ed.), Culture - Meaning Architecture: Critical Reflections on the Work of Amos Rapoport. Brookfield: Ashgate Publishing Company.

Rapport, N., \& Dawson, A. (1998). Migrants of Identity: Perceptions of Home in a World of Movement. Oxford and New York: Berg.

Rogers, R., \& Gumuchdjjan, P. (1996). Cities For a Small Planet. London: Faber and Faber Limited.

Sarup, M. (1994). Home and Identity. In G. Robertson, M. Mash, L. Tickner, J. Bird, B. Curtis \& T. Putnam (Eds.), Traveller's Tales-Narratives of Home and Displacement (pp. 93). New York: Routledge.

Saunders, P. (1989). The Meaning of Home in Contemporary English Culture. Housing Studies, 4(3), 177192.

Siegrist, J. (2000). Place, Social Exchange and Health: Proposed Sociological Framework. Social Sceince and Medicine, 51(9), 1283-1293.

Silverman, D. (2000). Doing Qualitative Research : a Practical Handbook. Thousand Oaks, California: Sage Publications.

Smith, Michale E. (2014). Housing in Premodern Cities: Patterns of Social and Spatial Variation. ArchnetIJAR, International Journal of Architectural Research, 8(3), 207-222.

Smith, Ronald, \& Bugni, Valerie. (2002a). Architectural Sociology and Post-Modern Architectural Forms. Faculty Publications, Paper 4. Retrieved from http://digitalscholarship.unlv.edu/sociology_pubs/4 website:

Smith, Ronald, \& Bugni, Valerie. (2002b). Getting to a better future through Architecture and Sociology. Faculty Publications.

Smith, Ronald, \& Bugni, Valerie. (2002c). The Role of Architecture and Sociology in Organizational Development. Faculty Publications. Retrieved from http://digitalscholarship.unlv.edu/cgi/viewcontent.cgi?article=1000\&context=sociology_pubs website:

Smith, Ronald, \& Bugni, Valerie. (2003). Designed Physical Environments as Related to Selves, Symbols and Social Reality: a Proposal for a Humanistic Shift for Architecture. Humanity and Society, 26(4), 293-311.

Smith, Ronald, \& Bugni, Valerie. (2006). Symbolic Interaction Theory and Architecture. Faculty Publications, Paper 5. Retrieved from http://digitalscholarship.unlv.edu/sociology_pubs/5/ website:

Sommer, R. (1983). Social Design: Creating Buildings with People in Mind. Englewood Cliffs, Nwe Jersey: Prentice-Hall.

Steele, F. (1973). Physical Settings and Organizational Development. Reading MA: Addison-Wesley.

Steele, F. (1983). Making and Managing High-Quality Workplaces. New York: Teachers College Press. 


\section{ArchNet}

Tilley, Christopher, Keane, Webb, Kuchler, Susanne, Rowlands, Michael, \& Spyder, Patricia. (2006). Handbook of Material Culture. London: Sage Publications Ltd.

Warner, M. (2001). Building Social Capital: The Role of Local Government. The Journal of socio-economic, 30, 187-192.

Wilson, P.A. (1997). Building Social Capital: a Learning Agenda for the Twenty-First Century. Urban Studies, 34(5-6), 745-760.

Woolcock, M. (1998). Social Capital and Economic Development: Toward a Theoretical Synthesis and Policy Framework. Theory and Society, 27(2), 151-*208.

Yin, R.K. (2003). Case Study Research: Design and Methods. Thousand Oaks, London: New Delhi: Sage.

Zevi, Bruni. (1948). Architecture as Space. How to look at Architecture. Torino: Einaudi.

\section{AUTHORS}

Dr Raffaello Furlan

Assistant Professor, PhD

Qatar University, College of Engineering,

Department of Architecture and Urban Planning

Email address: raffur@gmail.com

Dr Laura Faggion

Email address: laurafaggion2@gmail.com 